OPEN ACCESS

Edited by:

Paloma Moncaleán,

Neiker Tecnalia, Spain

Reviewed by:

Elena Corredoira,

Spanish National Research Council

(CS/C), Spain

Shinjiro Ogita,

Prefectural University of Hiroshima,

Japan

*Correspondence:

Guangdong Wang

gdwang@njau.edu.cn

Specialty section:

This article was submitted to Plant Development and EvoDevo, a section of the journal

Frontiers in Plant Science

Received: 21 December 2017

Accepted: 09 January 2019

Published: 28 January 2019

Citation:

Wang G, Xu C, Yan S and Xu B (2019) An Efficient Somatic Embryo Liquid Culture System for Potential Use in Large-Scale and Synchronic

Production of Anthurium andraeanum

Seedlings. Front. Plant Sci. 10:29.

doi: $10.3389 /$ fpls.2019.00029

\section{An Efficient Somatic Embryo Liquid Culture System for Potential Use in Large-Scale and Synchronic Production of Anthurium andraeanum Seedlings}

\author{
Guangdong Wang ${ }^{1 *}$, Chuanying $X u^{1}$, Shuo $\mathrm{Yan}^{1}$ and Bin $\mathrm{X} u^{2}$ \\ ${ }^{1}$ College of Horticulture, Nanjing Agricultural University, Nanjing, China, ${ }^{2}$ College of Agro-grassland Science, Nanjing \\ Agricultural University, Nanjing, China
}

Anthurium andraeanum Lind. is the second most important tropical flower in the world flower market. Somatic embryogenesis and plant regeneration in Anthurium has been reported previously; however, a stable and effective method for its commercial use has not been available. In this study, an efficient somatic embryogenesis and liquid culture system for large-scale production of $A$. andraeanum seedlings was achieved. Building on previous research, this study investigated the main factors for proembryogenic mass (PEM) proliferation, somatic embryo (SE) development, and SE germination in Anthurium. The results showed that relatively low concentrations of plant growth regulators, mineral nutrition, and sucrose promoted PEM proliferation, SE formation, and germination in a liquid culture system. This system can be described as follows: PEMs were induced from leaf blade explants on Murashige \& Skoog (MS) medium with half-strength MS macronutrients (1/2 MS) containing $2.0 \mathrm{mg} \mathrm{L}^{-1}$ 2,4-dichlorophenoxyacetic acid (2,4-D), $0.5 \mathrm{mg} \mathrm{L}^{-1}$ kinetin (KT), and $3 \%$ sucrose and were proliferated in $1 / 2 \mathrm{MS}$ liquid medium containing $1.0 \mathrm{mg} \mathrm{L}^{-1} 2,4-\mathrm{D}, 0.5 \mathrm{mg} \mathrm{L}^{-1}$ $\mathrm{KT}$, and $3 \%$ sucrose. The highest proliferation coefficients were 5.11-5.16. PEMs were then transferred to MS medium with 1/8 MS macronutrients (1/8 MS) liquid medium containing $1 \%$ sucrose to develop into globular embryos and mature embryos. Finally, the mature embryos were placed on four layers of absorbent filter paper saturated with 1/8 MS liquid medium containing 1\% sucrose for germination, and an average of 60 seedlings per gram SEs was obtained. This liquid culture system can be used in large-scale and synchronic production of Anthurium seedlings.

Keywords: Anthurium andraeanum, somatic embryogenesis, liquid culture, PEM proliferation, SE development, SE germination

\section{INTRODUCTION}

Anthurium andraeanum Lind. belongs to the Araceae family. It is famous for its showy spathe and beautiful foliage and has been the second most important tropical flower (next to orchid) in the world flower market (Dufour and Guerin, 2003; Teixeira da Silva et al., 2015). In 1956, growers in Holland first produced Anthurium for commercial purposes, mainly through seeding propagation 
or reproductive ramets (Kunisaki, 1980). Pierik et al. (1974) first reported successful establishment of a tissue culture system for Anthurium that was later adopted for commercial propagation in the industry.

Typically, Anthurium tissue cultures have been established by organogenesis from leaf, petiole, spathe, or axillary bud explants, and multiple shoots can be proliferated through a repeated callus-induction and regeneration process or axillary shoot proliferation (Pierik, 1976; Pierik et al., 1979; Geier, 1990; Martin et al., 2003; Puchooa, 2005; Teixeira da Silva et al., 2015). However, this method has several disadvantages, including low propagation efficiency, occasional somaclonal variation, and inhomogeneity (Kuehnle et al., 1992). Such limitations are among the key factors that cause the high market price of Anthurium seedlings. On the other hand, somatic embryogenesis is an effective micropropagation method that can overcome the shortcomings described above and has been successfully used for many kinds of economically valuable plants (Merkle et al., 1990; Duoue et al., 2006; Klimaszewska et al., 2015).

Somatic embryogenesis and plant regeneration in Anthurium was reported first by Kuehnle et al. (1992), and further studied from 1996 to 2016 (Matsumoto et al., 1996; Xin et al., 2006; Bautista et al., 2008; Pinheiro et al., 2013, 2014; Bhattacharya et al., 2016). In these studies, the combination of $1.0-4.0 \mathrm{mg} \mathrm{L}^{-1}$ of 2,4-dichlorophenoxyacetic acid $(2,4-\mathrm{D})$ and 0.33-0.5 $\mathrm{mg} \mathrm{L}^{-1}$ kinetin (KT) was found to be the key factor in proembryogenic mass (PEM) induction, and $0.5-1.0 \mathrm{mg} \mathrm{L}^{-1}$ $\mathrm{N}^{6}$-benzyladenine (6-BA) is also known to be important in somatic embryo (SE) development and plant regeneration. However, other factors influencing PEM proliferation and SE development were not compared systematically. Thus, a stable and effective system of somatic embryogenesis for the large-scale production of seedlings in Anthurium has not been available.

Clonal propagation through solid-medium tissue culture limits the mass production of Anthurium seedlings for commercial use because it requires highly skilled manual labor and lacks an automated production process. Somatic embryogenesis in liquid medium is a high efficient method that can solve this problem due to advantages such as rapid, homogeneous growth; thus, it can easily meet the requirements for automated production (Ruffoni and Savona, 2005). This technique has been used in micropropagation of conifer trees (Gupta and Timmis, 2005; Klimaszewska et al., 2015), Medicago truncatula (Duoue et al., 2006), sugarcane (Andibrisibe et al., 1994), and banana (Gómez Kosky et al., 2002), yet such a system had not been reported for Anthurium.

To establish a stable and effective somatic embryogenesis and propagation system for Anthurium using liquid culture, the main factors influencing embryogenic callus proliferation and SE development were compared in this study. By dividing the whole culture system into four steps-PEM induction, PEM proliferation, SE formation and SE germination-we optimized each step to establish an comlete liquid propagation system via somatic embryogenesis in Anthurium. Such a system could be useful for Anthurium seedling mass production for commercial use; additionally, this system could also provide a basic method for propagation using bioreactors for large-scale, synchronic production and genetic transformation of Anthurium seedlings in the future.

\section{MATERIALS AND METHODS}

\section{Pro-embryogenic Mass (PEM) Induction}

The methods described by Kuehnle et al. (1992) and Xin et al. (2006) were used for PEM induction. Fully expanded leaf blades of aseptic seedlings of A. andraeanum 'Amigo,' 'Valentino,' and 'Sonate' were used as explants ('Amigo' was used for the factor experiments; 'Valentino' and 'Sonate' were used to test the optimized protocol on other cultivars. PEM induction was initiated by cutting leaves (not including the edges) into square pieces approximately $0.8 \mathrm{~cm} \times 0.8 \mathrm{~cm}$ and culturing the pieces on solid Murashige \& Skoog (MS) medium (Murashige and Skoog, 1962) with half strength MS macronutrients (1/2 MS) $(1 / 2 \mathrm{MS}=$ half-strength MS macronutrients) and containing 3\% (w/v) sucrose, $2.0 \mathrm{mg} \mathrm{L}^{-1}$ 2,4-D, $0.5 \mathrm{mg} \mathrm{L}^{-1} \mathrm{KT}$, and $5.5 \%$ $(\mathrm{w} / \mathrm{v})$ agar, with the $\mathrm{pH}$ adjusted to 5.5. The leaf pieces were cultured for 45 days (d) in darkness at $25 \pm 1^{\circ} \mathrm{C}$. Dark brown non-embryogenic calluses were often induced earlier than PEMs, but did not develop further. By contrast, PEMs were induced at a later stage, but grew rapidly once induced and formed ball-like structures with nodulous appearance and fresh yellow color.

TABLE 1 | Effects of different concentrations of 2,4-D and sucrose on proliferation of Anthurium embryogenic callus (PEMs).

\begin{tabular}{lcc}
\hline $\begin{array}{l}\text { 2,4-D concentration } \\
\text { (mg L-1) }\end{array}$ & Sucrose (\%) & $\begin{array}{c}\text { Proliferation } \\
\text { coefficient }\end{array}$ \\
\hline 1.0 & 2.0 & $5.11 \mathrm{a}$ \\
& 3.0 & $5.16 \mathrm{a}$ \\
& 4.0 & $4.32 \mathrm{bc}$ \\
& 5.0 & $3.92 \mathrm{c}$ \\
2.0 & 6.0 & $3.43 \mathrm{de}$ \\
& 2.0 & $4.58 \mathrm{~b}$ \\
& 3.0 & $2.98 \mathrm{e}$ \\
& 4.0 & $2.28 \mathrm{f}$ \\
3.0 & 5.0 & $2.23 \mathrm{f}$ \\
& 6.0 & $2.16 \mathrm{f}$ \\
& 2.0 & $3.39 \mathrm{de}$ \\
4.0 & 3.0 & $2.48 \mathrm{f}$ \\
& 4.0 & $2.28 \mathrm{f}$ \\
& 5.0 & $1.65 \mathrm{~g}$ \\
& 6.0 & $1.59 \mathrm{~g}$ \\
& 2.0 & $3.46 \mathrm{~d}$ \\
& 3.0 & $1.66 \mathrm{~g}$ \\
& 4.0 & $1.66 \mathrm{~g}$ \\
& 5.0 & $1.64 \mathrm{~g}$ \\
& 6.0 & $1.63 \mathrm{~g}$ \\
\hline
\end{tabular}

The basal medium was $1 / 2 \mathrm{MS}$ containing $0.5 \mathrm{mg} \mathrm{L}^{-1} \mathrm{KT}$. Data were measured after 30 days of culture. Means followed by the same letter were not significantly different at 0.05 level. 

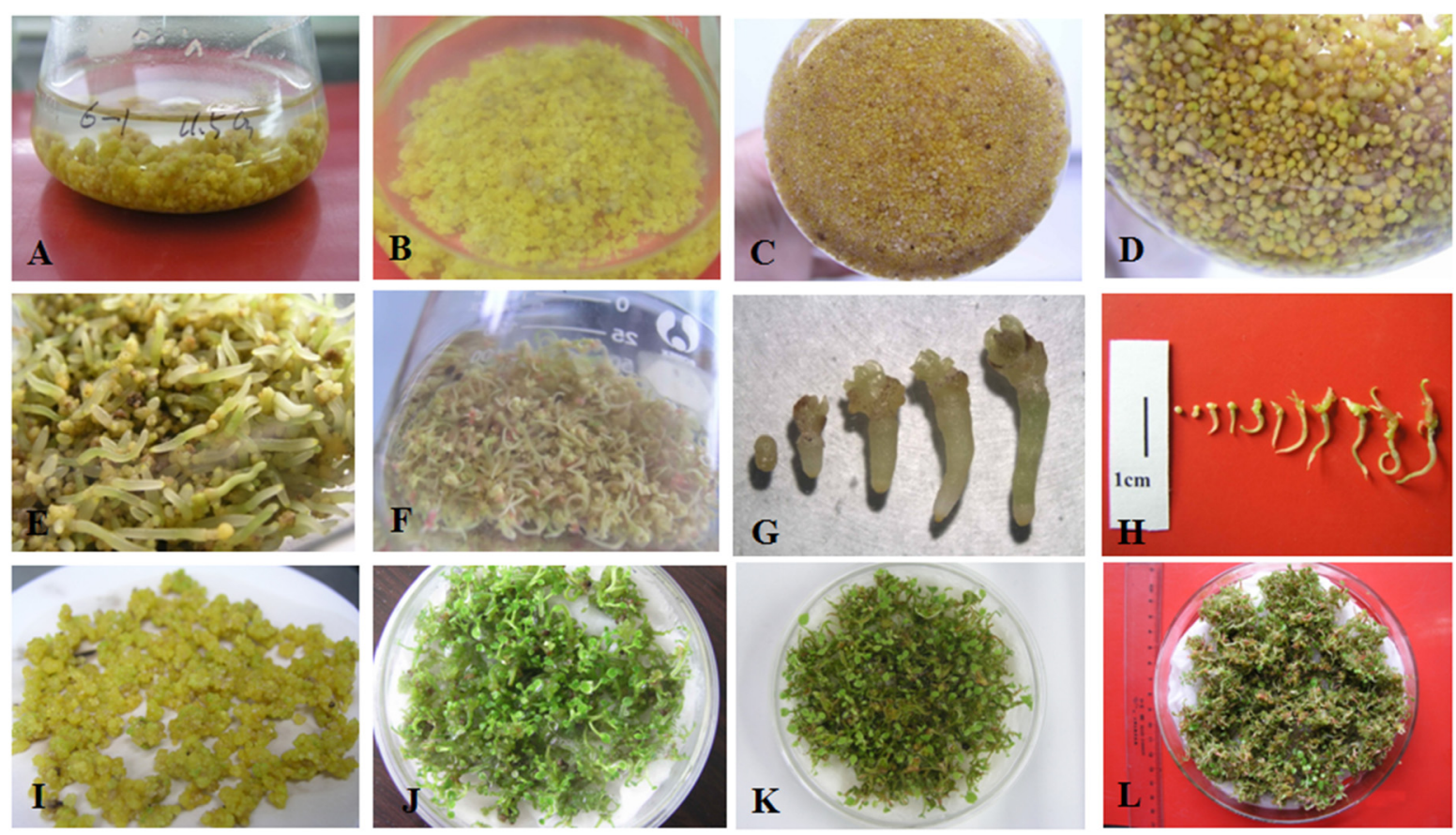

FIGURE 1 | Somatic embryo proliferation, development, and germination of Anthurium andraeanum. (A) Embryogenic callus (PEMs) of 'Amigo' proliferating in liquid culture. (B,C) Embryogenic callus fragmented by tweezers during subculture. (D) Development of somatic embryos (SEs) after reducing the concentrations of PGRs, sucrose, and basal medium in liquid culture. Development and germination of SEs of 'Amigo' (E) and 'Valentino' (F) in liquid culture. Somatic embryogenesis of 'Amigo' (G) and 'Valentino' (H) grown in liquid culture. (I) Developed SEs of 'Amigo' in preparation for raft culture. Plantlets germinating in raft cultures of SEs of 'Amigo' (J), 'Valentino' (K), and 'Sonate' (L).

\section{Liquid Culture for PEM Proliferation}

The granular PEMs, which formed from the edges of the sliced leaf blades, were then transferred into $150-\mathrm{ml}$ flasks with $75 \mathrm{ml}$ liquid medium containing the same nutrient and hormonal composition as the PEM induction medium except as otherwise stated. The liquid cultures were rotated at $100 \mathrm{rpm}$ at $25 \pm 1^{\circ} \mathrm{C}$, under scattered light at $20 \mu \mathrm{mol} \mathrm{m}^{-2} \mathrm{~s}^{-1}$. Proliferated PEMs in good condition were selected for proliferation experiments.

To test the liquid medium composition for PEM proliferation, 2,4-D at 1.0, 2.0, 3.0, or $4.0 \mathrm{mg} \mathrm{L}^{-1}$ and sucrose at $2,3,4,5$, or $6 \%(\mathrm{w} / \mathrm{v})$ were tested in all possible combinations by inoculation with $1.0 \mathrm{~g}$ PEM per $75 \mathrm{ml}$ liquid medium. The basal medium was $1 / 2 \mathrm{MS}$ containing $0.5 \mathrm{mg} \mathrm{L}^{-1} \mathrm{KT}$. The PEMs were transferred to the same liquid medium every 10 days during the culture period. The proliferation coefficients were recorded after 30 days culture and calculated as follows:

Proliferation coefficient $=$ fresh weight of PEMs after 30 days of culture/fresh weight of inoculated PEMs.

The effect of initial inoculum amount was also studied with initial PEM inoculum at 1.0, 2.0,3.0, or $4.0 \mathrm{~g}$ per $75 \mathrm{ml}$ liquid medium with $3 \%$ sucrose and $2.0 \mathrm{mg} \mathrm{L}^{-1} 2$,4-D. The basal medium was $1 / 2 \mathrm{MS}$ containing $0.5 \mathrm{mg} \mathrm{L}^{-1} \mathrm{KT}$. The fresh weight and proliferation coefficient of PEMs was recorded by weighing every 5 days during a 60 -days continuous culture period.

Each treatment was performed three times. The proliferation coefficients were calculated as follows:

Proliferation coefficient $=$ fresh weight of PEMs after the

$$
\begin{aligned}
& \text { specified time in culture }(0-60 \\
& \text { days)/fresh weight of inoculated } \\
& \text { PEMs. }
\end{aligned}
$$

\section{Liquid Culture for Somatic Embryo (SE) Induction}

The proliferated granular PEMs were used to induce SEs in liquid culture. MS medium containing different strengths of MS macronutrients $(1 / 8,1 / 4,1 / 2$, MS) and sucrose concentrations $(0,1,2,3 \%)$ were tested for their effect on SE induction in the absence of plant growth regulators (PGRs). The numbers of SEs of different sizes per $1.0 \mathrm{~g}$ PEMs were recorded after 15 and 30 days. The transfer interval was 10 days and the other culture conditions were the same as for PEM proliferation.

Liquid medium with different $\mathrm{NH}_{4} \mathrm{NO}_{3}$ levels relative to fullstrength MS medium (i.e., $1 / 2,1 / 4,1 / 8$, and $0 \mathrm{NH}_{4} \mathrm{NO}_{3}$ ), $1 \%$ sucrose, and no PGRs was used for SE development on MS or $1 / 2$ MS basal medium lacking $\mathrm{NH}_{4} \mathrm{NO}_{3}$. PEMs $(1.0 \mathrm{~g})$ were 
inoculated into 150 - $\mathrm{ml}$ flasks containing $75 \mathrm{ml}$ of liquid medium, and the SE number per gram PEMs was recorded after 30 days of culture. The transfer period was 10 days, and the other culture conditions were the same as for primary proliferation.

\section{Liquid and Raft Culture for SE Germination}

First, different concentrations $\left(0,0.25,0.5,1.0 \mathrm{mg} \mathrm{L}^{-1}\right)$ of PGRs (BA, KT, and gibberellic acid $\left[\mathrm{GA}_{3}\right]$ ) were compared for their effects on SE germination with $0.5 \mathrm{~g}$ SEs in $75 \mathrm{ml}$ of liquid medium at a rotating speed of $100 \mathrm{rpm}$. Second, rotating liquid culture and raft culture were compared for their effect on SE germination with $1 / 8 \mathrm{MS}$ basal medium and $1 \%$ sucrose, under $20 \mu \mathrm{mol} \mathrm{s}{ }^{-2} \mathrm{~s}^{-1}$ light intensity. For raft culture, $0.5 \mathrm{~g}$ SEs were placed on four layers of absorbent filter paper saturated with liquid medium in a Petri dish, and were transferred to new medium every 15 days. The number of germinated SEs (i.e., those with root length longer than SE diameter) per gram of SEs was recorded after 30 days of culture.

\section{Statistical Analysis}

All treatments were performed three times. Each treatment contained 10 Erlenmeyer flasks (liquid culture) or Petri dishes (raft culture). SPSS Base 8.0 software and Excel software for Windows were used for statistical analysis. Data were analyzed using the two-way ANOVA method.

\section{RESULTS}

We divided the whole somatic embryogenesis system into four steps: PEM induction, PEM proliferation, SE induction, and SE germination. The PEM induction system has been reported previously (Xin et al., 2006). In the present study, we optimized the remaining three steps in liquid culture.

\section{PEM Proliferation in Liquid Culture}

To proliferate PEMs, we first tested 20 different combinations of 2,4-D and sucrose concentrations on their effects on PEM proliferation (Table 1). A pilot experiment showed that supplementation with $2,4-\mathrm{D}$ and sucrose was necessary to maintain PEM status, yet with increasing concentrations of either 2,4-D or sucrose, the proliferation coefficient of PEMs decreased (Table 1). The highest proliferation coefficients (5.11-5.16) were achieved with $1.0 \mathrm{mg} \mathrm{L}^{-1} 2,4-\mathrm{D}$ and $2-3 \%$ sucrose after 30 days of culture. In addition, the PEMs also became more nodulous and friable with lower concentrations of 2,4-D and sucrose (data not shown). In general, PEMs of the best quality (light yellow color and friable texture) were obtained with 1.0-2.0 $\mathrm{mg} \mathrm{L}^{-1} 2,4-\mathrm{D}$ and 3-4\% sucrose (Figure 1A). Taking these observations together, we concluded that $1 / 2 \mathrm{MS}$ supplemented with $1.0 \mathrm{mg} \mathrm{L}^{-1} 2,4-\mathrm{D}$, $3 \%$ sucrose, and $0.5 \mathrm{mg} \mathrm{L}^{-1} \mathrm{KT}$ was the optimal medium for PEM proliferation in liquid culture.

In our pilot experiment, we also observed that under continuous culture without separation of the proliferated PEMs, the proliferation rate (i.e., the increase in fresh weight over time) followed an S-shaped curve. Therefore, we tested the

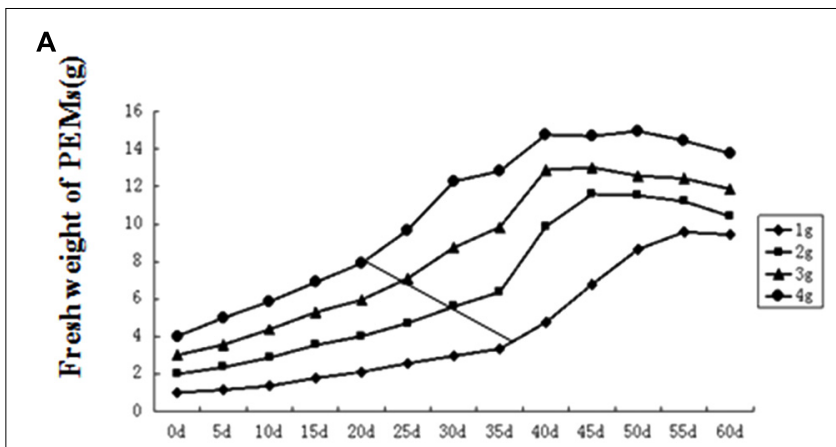

B

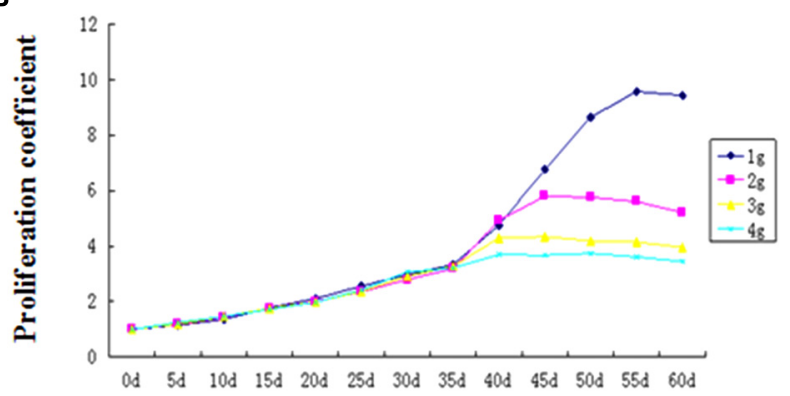

FIGURE 2 | Proembryogenic mass (PEM) proliferation curves for different amounts of inoculum. (A) Proliferation rate curves (showing total fresh weight over time) for different inoculum amounts. (B) Proliferation coefficient curves (showing fresh weight of culture/fresh weight of inoculum) for different inoculum amounts. The diagonal line in (A) indicates the inflection point (between slow growth and logarithmic growth) in each curve.

effect of initial PEM inoculum amount on proliferation. As shown in Figure 2A, under continuous culture for 60 days, the proliferation rate curve can be divided into three stages: (1) initial slow growth, (2) logarithmic phase, and (3) stationary and decline phase. With higher amounts of initial inoculum, the inflection of the proliferation rate curve occurred earlier; in the logarithmic stage, the lower the amount of initial inoculum, the steeper the slope of the proliferation rate curve (corresponding to a higher proliferation coefficient; Figure 2B). As time in culture increased, the PEMs became more nodulous and scattered with some developing into SEs; the PEMs eventually turned brown and became necrotic at the stationary and decline stage. To avoid the occurrence of sporadic SE induction while maintaining a highly homogenous PEM culture, we concluded that the optimal inoculum amount for $75 \mathrm{ml}$ of liquid medium was $\sim 1 \mathrm{~g}$ of PEM and the optimal transfer period was approximately 25 days (see Discussion for further explanation).

\section{Homogenous Somatic Embryo (SE) Induction in Liquid Culture}

To induce somatic embryogenesis from PEMs, combinations of different strengths of MS basal medium and sucrose concentrations were tested. As shown in Table 2, reduced basal medium strength was critical for SE induction, and low sucrose concentration (1\%) also improved SE induction. 
TABLE 2 | Effects of basal medium strength and sucrose on somatic embryogenesis of Anthurium embryogenic callus (PEMs).

\begin{tabular}{|c|c|c|c|c|c|c|}
\hline \multirow[t]{2}{*}{ Basal medium strength } & \multirow[t]{2}{*}{ Sucrose (\%) } & \multicolumn{3}{|c|}{15 days after inoculation } & \multicolumn{2}{|c|}{30 days after inoculation } \\
\hline & & $\begin{array}{c}\text { SE number } \\
\text { (diameter } \\
\geq 1 \mathrm{~mm} \text { )/g PEMs }\end{array}$ & $\begin{array}{c}\text { SE number } \\
\text { (diameter } \\
\geq 2 \mathrm{~mm} \text { )/g PEMs }\end{array}$ & $\begin{array}{c}\text { SE number } \\
\text { (diameter } \\
\geq 3 \mathrm{~mm} \text { )/g PEMs }\end{array}$ & $\begin{array}{c}\text { SE number } \\
\text { (diameter } \\
\geq 2 \mathrm{~mm} \text { )/g PEMs }\end{array}$ & $\begin{array}{c}\text { SE number } \\
\text { (diameter } \\
\geq 3 \mathrm{~mm} \text { )/g PEMs }\end{array}$ \\
\hline \multirow[t]{4}{*}{ MS } & 0 & $19.3 f$ & Oe & Oc & 18.66de & Oc \\
\hline & 1 & $22.0 f$ & Oe & Oc & 2.66gh & Oc \\
\hline & 2 & $12.7 \mathrm{fg}$ & Oe & Oc & Oh & Oc \\
\hline & 3 & $10.7 \mathrm{fg}$ & Oe & Oc & Oh & Oc \\
\hline \multirow[t]{4}{*}{$1 / 2 \mathrm{MS}$} & 0 & $5.3 \mathrm{~g}$ & Oe & Oc & Oh & Oc \\
\hline & 1 & $11.3 \mathrm{fg}$ & Oe & Oc & 8.66fgh & Oc \\
\hline & 2 & $10.0 f g$ & Oe & Oc & Oh & Oc \\
\hline & 3 & $\mathrm{Og}$ & Oe & Oc & Oh & Oc \\
\hline \multirow[t]{4}{*}{$1 / 4 \mathrm{MS}$} & 0 & $5.3 \mathrm{~g}$ & Oe & Oc & Oh & Oc \\
\hline & 1 & $53.3 d$ & $14.0 \mathrm{c}$ & Oc & $36 c$ & Oc \\
\hline & 2 & $34.0 \mathrm{e}$ & $8.0 d$ & Oc & $16 \mathrm{ef}$ & Oc \\
\hline & 3 & $20.0 f$ & Oe & Oc & Oh & Oc \\
\hline \multirow[t]{4}{*}{ 1/8 MS } & 0 & $10.7 \mathrm{fg}$ & Oe & Oc & Oh & Oc \\
\hline & 1 & $126.7 \mathrm{a}$ & $60.7 a$ & $17.3 a$ & $156 a$ & $25.34 a$ \\
\hline & 2 & $88.0 b$ & $50.7 b$ & $12.0 \mathrm{~b}$ & $78 b$ & $11.34 b$ \\
\hline & 3 & $71.3 c$ & $11.3 \mathrm{~cd}$ & Oc & $24.66 d$ & Oc \\
\hline
\end{tabular}

Data were measured after 30 days of culture. Means in the same column followed by the same letter were not significantly different at 0.05 level.

TABLE 3 | Effect of $\mathrm{NH}_{4} \mathrm{NO}_{3}$ on somatic embryogenesis of Anthurium embryogenic callus (PEMs).

\begin{tabular}{|c|c|c|c|c|c|}
\hline $\begin{array}{l}\text { Basal } \\
\text { medium }\end{array}$ & $\begin{array}{l}\text { Ratio of } \\
\mathrm{NH}_{4} \mathrm{NO}_{3}\end{array}$ & $\begin{array}{l}\text { Proliferation } \\
\text { coefficient }\end{array}$ & $\begin{array}{c}\text { SE number } \\
(\geq 1 \mathrm{~mm}) / \mathrm{gPEMs}\end{array}$ & $\begin{array}{c}\text { SE number } \\
(\geq 2 \mathrm{~mm}) / \mathrm{gPEMs}\end{array}$ & $\begin{array}{c}\text { SE number } \\
(\geq 4 \mathrm{~mm}) / \mathrm{gPEMs}\end{array}$ \\
\hline \multirow[t]{4}{*}{ MS } & $1 / 2$ & $3.68 \mathrm{e}$ & $10.0 c$ & Oe & Oc \\
\hline & $1 / 4$ & $4.46 d$ & $43.34 b$ & $5.34 \mathrm{de}$ & Oc \\
\hline & $1 / 8$ & $5.67 a$ & $50.0 \mathrm{~b}$ & $13.34 c$ & Oc \\
\hline & 0 & 5.35ab & $75.34 a$ & $36.66 a$ & $16.0 \mathrm{a}$ \\
\hline \multirow[t]{4}{*}{$1 / 2 \mathrm{MS}$} & $1 / 2$ & $3.66 \mathrm{e}$ & $6.66 c$ & Oe & Oc \\
\hline & $1 / 4$ & $4.68 \mathrm{~cd}$ & $46.66 b$ & $5.34 \mathrm{de}$ & Oc \\
\hline & $1 / 8$ & 4.99bcd & $50.0 \mathrm{~b}$ & $8.66 c d$ & Oc \\
\hline & 0 & $5.23 a b c$ & $68.66 \mathrm{a}$ & $30.66 b$ & $10.66 b$ \\
\hline
\end{tabular}

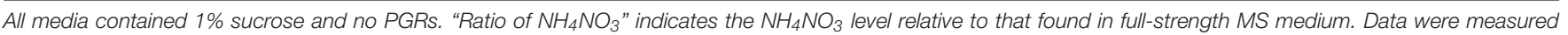
after 30 days of culture. Means followed by the same letter were not significantly different at 0.05 level.

The best result was from the combination of $1 / 8 \mathrm{MS}$ and $1 \%$ sucrose, which yielded an average of 126.7 SEs $(\geq 1 \mathrm{~mm}$ diameter) out of $1.0 \mathrm{~g}$ inoculated PEMs by 15 days after inoculation. The induced SEs were also highly homogenous, i.e., nearly all induced SEs were at the globular stage (Figure 1D). On the other hand, with increased induction time, the number of SEs stayed the same after 30 days of culture, but the average size $(\geq 2 \mathrm{~mm})$ of the induced SEs increased (Table 2).

In addition, we examined the effects of $\mathrm{NH}_{4} \mathrm{NO}_{3}$ on $\mathrm{SE}$ proliferation. The results showed that the concentration of $\mathrm{NH}_{4} \mathrm{NO}_{3}$ in the liquid medium had a very significant effect on SE development (Table 3). The number of SEs increased significantly with reduced $\mathrm{NH}_{4} \mathrm{NO}_{3}$ levels in either MS or $1 / 2 \mathrm{MS}$ basal medium, but there was no overall difference between MS basal medium and 1/2 MS basal medium at the same $\mathrm{NH}_{4} \mathrm{NO}_{3}$ level according to ANOVA analysis.
There were green protuberances on the surface of the PEM when the $\mathrm{NH}_{4} \mathrm{NO}_{3}$ level was high. The $\mathrm{SE}$ and radicle developed better with reduced $\mathrm{NH}_{4} \mathrm{NO}_{3}$ levels, with a maximal SE number when cultured in MS or $1 / 2 \mathrm{MS}$ basal medium without $\mathrm{NH}_{4} \mathrm{NO}_{3}$. However, the plumule pole was merged more significantly and the SEs were less homogeneous in the liquid medium with low $\mathrm{NH}_{4} \mathrm{NO}_{3}$ than in liquid medium containing 1/8 MS and 1\% sucrose.

\section{SE Germination in Raft Culture}

To test germination conditions, the homogenous SEs were germinated either in rotating liquid culture or in raft culture and with or without PGRs (BA, KT, GA 3 ). Supplementation with BA, $\mathrm{KT}$, or $\mathrm{GA}_{3}$ all suppressed SE germination, and raft culture was more effective for SE germination than rotating liquid culture (Table 4). The highest number of germinated seedlings from SE was achieved on raft culture without PGR supplementation; 
TABLE 4 | Comparison of raft and rotating liquid culture and effects of plant growth regulators on germination of Anthurium somatic embryos.

\begin{tabular}{|c|c|c|c|}
\hline Culture method & $\begin{array}{l}\text { Plant growth } \\
\text { regulator }\end{array}$ & $\begin{array}{c}\text { Concentration } \\
\left(\mathrm{mg} \mathrm{L}^{-1}\right)\end{array}$ & $\begin{array}{c}\text { No. of } \\
\text { germinated } \\
\text { seedlings per } \\
\text { g of SEs }\end{array}$ \\
\hline \multirow[t]{10}{*}{ Raft culture } & - & - & $60.0 a$ \\
\hline & $\mathrm{BA}$ & 0.25 & $13.3 \mathrm{c}$ \\
\hline & & 0.5 & $12.0 \mathrm{cde}$ \\
\hline & & 1.0 & $20.7 b$ \\
\hline & $\mathrm{KT}$ & 0.25 & $12.7 \mathrm{~cd}$ \\
\hline & & 0.5 & $12.7 \mathrm{~cd}$ \\
\hline & & 1.0 & $12.7 \mathrm{~cd}$ \\
\hline & $\mathrm{GA}_{3}$ & 0.25 & 8.0cdefg \\
\hline & & 0.5 & 4.7efg \\
\hline & & 1.0 & $0.7 \mathrm{~g}$ \\
\hline \multirow[t]{10}{*}{ Rotating liquid culture } & - & - & $15.3 b c$ \\
\hline & BA & 0.25 & 5.3defg \\
\hline & & 0.5 & 4.7efg \\
\hline & & 1.0 & $3.3 f g$ \\
\hline & $\mathrm{KT}$ & 0.25 & 5.3defg \\
\hline & & 0.5 & 4.7efg \\
\hline & & 1.0 & 9.3cdef \\
\hline & $\mathrm{GA}_{3}$ & 0.25 & $2.0 f g$ \\
\hline & & 0.5 & 5.3defg \\
\hline & & 1.0 & 4.7efg \\
\hline
\end{tabular}

Data were measured after 30 days of culture. Means followed by the same letter were not significantly different at 0.05 level.

under these conditions, an average of 60 seedlings germinated from $1 \mathrm{~g}$ of SEs after 30 days of culture (Table 4). Moreover, in the raft cultures, radicles of the germinated SEs rapidly elongated with white root hairs, and shoots developed after radicle elongation. By contrast, in liquid culture, the radicles grew slower and with no root hairs, and secondary SEs often emerged at the pole of the plumule even in the absence of PGRs (Figures 1E-J). All the germinated SEs could grow into normal plantlets.

\section{Additional Genotypes}

This system development described above was performed using 'Amigo.' The optimized micropropagation system (see section "Conclusion") was successfully applied to two other cultivars of Anthurium, 'Valentino' and 'Sonate' (Figures 1F,H,K,L).

\section{DISCUSSION}

Micropropagation via somatic embryogenesis is a more desirable method than via organogenesis from callus owing to high culture homogeneity and ease of using a low-cost liquid culture system (Merkle et al., 1990). Somatic embryogenesis and plant regeneration in solid culture has been reported in Anthurium (Kuehnle et al., 1992; Xin et al., 2006; Bautista et al., 2008; Pinheiro et al., 2013, 2014; Bhattacharya et al., 2016), but a complete liquid culture system including proliferation of PEMs, their inducible transition to homogenous SEs, and SE germination has not previously been reported for A. andraeanum.

\section{Key Factors in PEM Proliferation in Liquid Culture}

Proembryogenic mass are in fact a solid cluster of SEs at an early development stage (von Arnold et al., 2002). The state of PEMs induced from leaf explants in the present study was similar to that of the embryogenic calli described by Kuehnle et al. (1992) and Bautista et al. (2008). In this study, PEMs rather than callus or developed mature SEs were used for proliferation because of the easier maintenance of the homogenous developmental state and the inducible transition from PEMs to SEs. It was reported that 2,4-D was very important for the induction of Anthurium SEs (Kuehnle et al., 1992; Hamidah et al., 1997b; Xin et al., 2006; Bautista et al., 2008). Regarding the somatic embryogenesis of $A$. andraeanum (Kuehnle et al., 1992) or A. scherzerianum (Hamidah et al., 1997b), relatively high concentrations of 2,4-D $\left(18 \mu \mathrm{mol} \mathrm{L}^{-1}\right)$ and carbohydrate ( $4 \%$ sucrose plus $2 \%$ glucose) can induce PEMs effectively. However, in our study, we found that the proliferation coefficient of PEMs cultured in liquid medium fell with increasing concentrations of 2,4-D and sucrose. The reason behind this might be that induction of PEM was related to stress that occurred under high osmotic pressure (e.g., by using a high concentration of sucrose; Stasolla and Yeung, 2003) and under high concentration of auxin, especially with 2,4-D, an auxin analog and a dicot herbicide when at high concentrations (Coca et al., 1994; Kitamiya et al., 2000; Fehér et al., 2001). Once PEMs were induced, their proliferation no longer required high concentration of 2,4-D. Furthermore, liquid culture allows rapid nutrient uptake by cells and speedy nutrient replacement at the cell surface via diffusion. Thus, lower nutrient levels are usually optimal during PEM proliferation compared to those typically used in solid media (Gupta and Timmis, 2005).

\section{Homogeneity of PEMs During Proliferation in Liquid Culture Condition}

In plant cell suspension culture, the proliferation curves are typically S-shaped, as in the cases of Angelica sinensis (Oliv.) (Tsay and Huang, 1998), avocado (Witjaksono and Litz, 1999), and date palm (Fki et al., 2003). In this study, a long period

\begin{tabular}{|c|c|c|c|c|c|}
\hline \multirow[t]{2}{*}{$\begin{array}{l}\text { PEM } \\
\text { induction }\end{array}$} & \multirow[t]{2}{*}{$\begin{array}{l}\text { PEM } \\
\text { proliferation }\end{array}$} & \multirow{2}{*}{$\begin{array}{l}\text { SE } \\
\text { formation }\end{array}$} & \multirow{2}{*}{$\begin{array}{l}\text { SE } \\
\text { development }\end{array}$} & \multicolumn{2}{|c|}{$\begin{array}{l}\text { SE } \\
\text { germination }\end{array}$} \\
\hline & & & & $\lim _{1}$ & \\
\hline \multicolumn{2}{|c|}{$\begin{array}{l}\text { High level of } \\
2,4-\mathrm{D}, \text { Sucrose, } \mathrm{KT}, 1 / 2 \mathrm{MS}\end{array}$} & 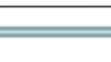 & $\Rightarrow \quad$ Low level & rose, & \\
\hline \multicolumn{6}{|c|}{$\begin{array}{l}\text { FIGURE } 3 \text { | Process of somatic embryogenesis from PEM induction to SE } \\
\text { germination in Anthurium liquid culture system. }\end{array}$} \\
\hline
\end{tabular}




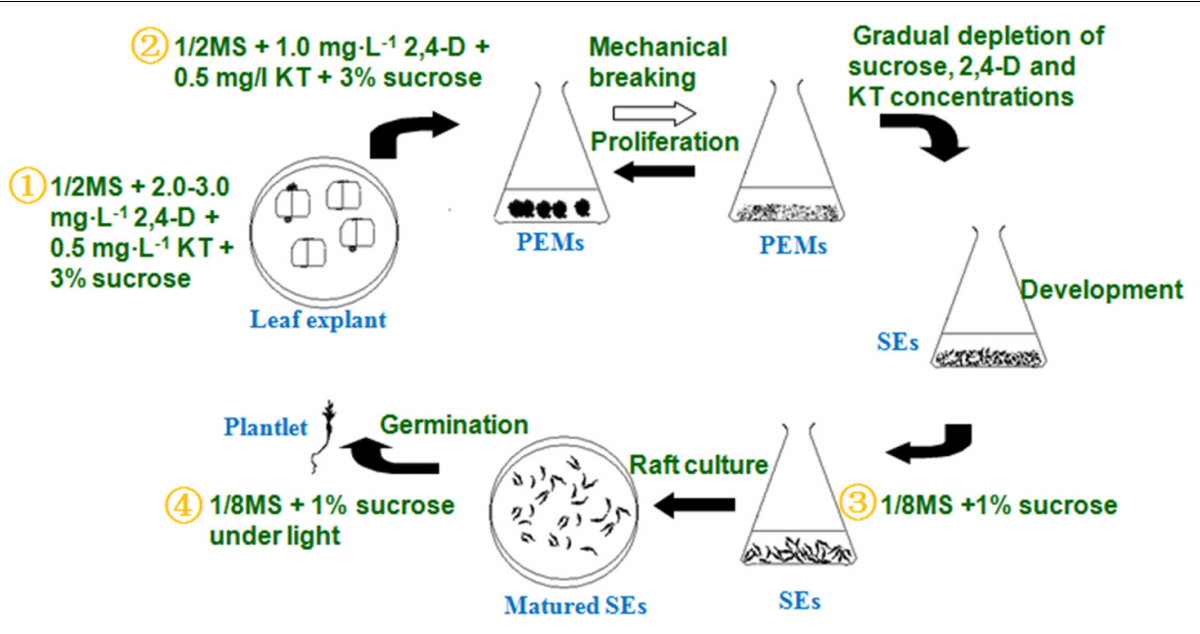

FIGURE 4 | Detailed liquid micropropagation procedure for $A$. andraeanum 'Amigo' via SEs.

of logarithmic growth was observed at the early stage of proliferation (Figure 2A). This might be because the proliferation materials were PEMs rather than suspension cells. In liquid culture, the outer layer of PEMs would be in full contact with culture medium, but the inner cells might be restricted from growth due to less growth stimulus from the culture medium and to physical restraint by the outer layers of PEMs. During the rotating liquid culture, the PEMs often fell apart into smaller, friable parts that adapted to the liquid culture condition (e.g., Figures 1B,C), thereby slowly reaching the flexion of proliferation.

On the other hand, the induction of SEs could sporadically occur during proliferation. Since our results showed that lower concentrations of PGRs or nutrients in the liquid medium could induce SEs, the appearance of SEs during the proliferation of PEMs in continuous culture might indicate that the PGRs and nutrients were gradually depleted during culture. It was also found in other plant species that lower concentrations of PGRs could induce SEs (Chol et al., 1999; Stasolla and Yeung, 2003). Therefore, we suggest that the inoculum amount and transfer period should be well-controlled, even at the expense of reducing the proliferation coefficient, to maintain highly homogenous PEMs because homogeneity could be one of the most important factors for commercial micropropagation. In the present study, the optimal inoculum amount for $75 \mathrm{ml}$ liquid medium was approximately $1.0 \mathrm{~g}$, and the optimal transfer period was approximately 25 days.

\section{Low Nutrient Concentration Was Critical for the Induction of SE in Anthurium}

Previously, different combinations of 6-BA or KT and their effects on SE induction, development, and germination have been reported in A. andraeanum (Kuehnle et al., 1992; Xin et al., 2006; Bautista et al., 2008) and A. scherzerianum (Hamidah et al., 1997b), yet our experimental results showed that lower levels of nutrients and sucrose, rather than PGRs, were critical for homogenous SE induction. We have also tested the effects of abscisic acid (ABA) on the development, maturation, and germination of SEs, but no significant differences were ever detected (data not shown), which was consistent with a report on A. scherzerianum (Hamidah et al., 1997a).

It was reported that a low level of $\mathrm{NH}_{4} \mathrm{NO}_{3}\left(200 \mathrm{mg} \mathrm{L}^{-1}\right)$ was beneficial for inducing regeneration in all genotypes of A. scherzerianum (Geier, 1986). Our experiment also showed that gradual reduction of $\mathrm{NH}_{4} \mathrm{NO}_{3}$ in MS and 1/2 MS basal medium promoted SE formation, but the effect was not as strong as that obtained by reducing all of the MS macronutrients, e.g., to $1 / 8$ MS (Tables 2, 3). The fact that lower levels of nutrients promoted SE induction was probably because SE formation was responsive to nutrient deficiency, similar to what had been found with cotton (Gossypium hirsutum) (Kumria et al., 2003).

\section{Depletion of PGRs Promoted SE Germination Under Raft Culture Conditions}

Both 6-BA and KT at low levels are common PGRs used in SE germination in some plants, such as rice (Oryza sativa), Camellia nitidissima, and Asparagus breslerianus (Rueb et al., 1994; Lü et al., 2013; Mousavizadeh et al., 2017), and these PGRs have also been used for SE germination in A. andraeanum (Kuehnle et al., 1992; Xin et al., 2006; Bautista et al., 2008) and A. scherzerianum (Hamidah et al., 1997b). $\mathrm{GA}_{3}$ is another PGR known for promoting SE germination in plants such as Eleutherococcus senticosus and Dianthus (Chol et al., 1999; Pareek and Kothari, 2003). However, in our experiment, supplementation with 6-BA, $\mathrm{KT}$, or $\mathrm{GA}_{3}$ at $0.25-1.0 \mathrm{mg} \mathrm{L}^{-1}$ inhibited the germination of SEs. Instead, $\mathrm{KT}$ and $\mathrm{GA}_{3}$ caused the formation of secondary embryos, while BA induced the formation of non-embryogenic callus (data not shown). This discrepancy between our study and previous studies could be due to the culture condition of SEs (liquid vs. solid-medium culture). In solid culture media (e.g., those solidified with agar or gellan gum), the uptake 
of nutrients by SEs was relatively slow, which could generate concentration gradients for each nutrient in the zone of the gel next to the cells (Gupta and Timmis, 2005). Liquid medium allowed the accumulation of nutrients and PGRs in the body of cultures during proliferation, at an earlier stage of development. Additional supplementation with extra PGRs could suppress germination of SEs. Compared to the submerged rotating liquid culture, the raft culture system was superior for SE germination, which could be due to the optimum oxygen concentration, low shear force, and normal gravity in the raft culture. In addition, raft culture provided lower water content conditions. It has been reported that desiccation treatment improved SE conversion and germination in alfalfa (Medicago sativa) and conifers (Lai and McKersie, 1994; von Arnold et al., 2002; Klimaszewska et al., 2015; Zhou et al., 2017). Our results were consistent with these previous reports.

\section{CONCLUSION}

A highly stable micropropagation system was established via somatic embryogenesis in A. andraeanum 'Amigo.' In the PEM induction stage, higher concentrations of 2,4-D, KT, and sucrose are necessary. However, lower concentrations of 2,4-D, mineral nutrition, and sucrose promoted PEM proliferation and SE development. Absorbent filter paper with decreased nutrition and hormone-free medium was suitable for SE germination (Figure 3).

This micropropagation system has been successfully applied to two other cultivars of Anthurium: 'Valentino' and 'Sonate.' Once PEMs were induced, PEM proliferation and SE development was very effective for in vitro seedling propagation of these two cultivars. However, specific optimizations might still be necessary for some other varieties.

The optimized somatic embryogenesis procedure can be summarized as follows (Figure 4):

1. PEM induction ( $\sim 45$ days): PEMs were induced from leaf blade explants on 1/2 MS solid medium containing

\section{REFERENCES}

Andibrisibe, E., Miyake, H., Taniguchi, T., and Maeda, E. (1994). Regulation of somatic embryogenesis in long-term callus cultures of sugarcane (Saccharum officinarum L.). New Phytol. 126, 301-307. doi: 10.1111/j.1469-8137.1994. tb03949.x

Bautista, N. D. R., Peñalver, D. A., Rodríguez, R. B., Chiu, W. C., López, R. C., and Terry, F. J., et al. (2008). Somatic embryogenesis in Anthurium andraeanum Lind. variety 'Lambada'. Ra Ximhai 4, 135-149.

Bhattacharya, C., Dam, A., Karmakar, J., and Bandyopadhyay, T. K. (2016). Direct somatic embryogenesis and genetic homogeneity assessment of regenerated plants of Anthurium andraeanum Linden cv. Fantasia. In Vitro Cell. Dev. Biol. Plant 52, 512-519. doi: 10.1007/s11627-016-9763-8

Chol, Y. E., Kim, J. W., and Yoon, E. S. (1999). High frequency of plant production via somatic embyogenesis from callus of cell suspension cultures in Eleutherococcus senticosus. Ann. Bot. 83, 309-314. doi: 10.1006/anbo.1998. 0827

Coca, M. A., Almoguera, C., and Jordano, J. (1994). Expression of sunflower lowmolecular-weight heat-shock proteins during embryogenesis and persistence
2-3 $\mathrm{mg} \mathrm{L}^{-1}$ 2,4-D, $0.5 \mathrm{mg} \mathrm{L}^{-1} \mathrm{KT}$, 3\% sucrose, and 5.5\% agar.

2. PEM proliferation ( $\sim 30-60$ days): PEMs were proliferated in $1 / 2 \mathrm{MS}$ liquid medium containing $1.0 \mathrm{mg} \cdot \mathrm{L}^{-1} 2,4-\mathrm{D}$, $0.5 \mathrm{mg} \cdot \mathrm{L}^{-1} \mathrm{KT}$, and $3 \%$ sucrose. Inoculum was $1.0 \mathrm{~g}$ PEMs per $75 \mathrm{ml}$ liquid culture, transferred every 25 days.

3. SE induction ( $\sim 30$ days): PEM fragments were transferred to $1 / 8 \mathrm{MS}$ liquid medium containing $1 \%$ sucrose to develop into globular embryos.

4. SE germination ( $\sim 30-60$ days): Mature embryos were added to four layers of absorbent filter paper saturated with $1 / 8$ MS liquid medium containing $1 \%$ sucrose for germination.

This liquid culture system provided a basic technique for large-scale, synchronic production of SEs and seedlings in Anthurium, which could have high commercial benefit. It also provided a basic technique for in vitro breeding, such as through genetic transformation or embryonic mutant induction.

Although the germinated seedlings from this system were identical in organogenesis and phenotype (data not shown), somaclonal variation is a problem in some species (von Arnold et al., 2002). Further studies are needed to determine whether somaclonal variation occurs in Anthurium seedlings developed by using this method.

\section{AUTHOR CONTRIBUTIONS}

GW designed the experiment and wrote the manuscript. CX, SY, $\mathrm{BX}$, and GW performed the experiment and data analysis.

\section{FUNDING}

This work was supported by the National Natural Science Foundation of China (Grant No. 30300244).

after germination: localization and possible functional implications. Plant Mol. Biol. 25, 479-492. doi: 10.1007/BF00043876

Dufour, L., and Guerin, V. (2003). Growth development features and flower production of Anthurium andraeanum Lind in tropical conditions. Sci. Hortic. 98, 25-35. doi: 10.1016/S0304-4238(02)00196-6

Duoue, A. S., Pires, A. S., Santos, D. M. D., and Fevereiro, P. (2006). Efficient somatic embryogenesis and plant regeneration from long-term cell suspension cultures of Medicago truncatula cv. Jemalong. In Vitro Cell. Dev. Biol. Plant. 42, 270-273. doi: 10.1079/IVP2006775

Fehér, A., Pasternak, T., Miskolczi, P., Ayaydin, F., and Dudits, D. (2001). Induction of the embryogenic pathway in somatic plant cells. Acta Hortic. 560, 293-298. doi: 10.17660/ActaHortic.2001.560.55

Fki, L., Masmoudi, R., Drira, N., and Rival, A. (2003). An optimised protocol for plant regeneration from embryogenic suspension cultures of date palm, Phoenix dactylifera L., cv. Deglet Nour. Plant Cell Rep. 21, 517-524. doi: 10.1007/s00299002-0558-5

Geier, T. (1986). Factors affecting plant regeneration from leaf segments of Anthurium scherzerianum Schott (Araceae) cultured in vitro. Plant Cell Tissue Organ. Cult. 6, 115-125. doi: 10.1007/BF00180795 
Geier, T. (1990). "Anthurium," in Handbook of Plant Cell Culture, Ornamental Species, vol. 5, eds P. V. Amirato, D. A. Evans, W. R. Sharp and Y. P. S. Bajaj (New York, NY: McGraw-Hill), 228-252.

Gómez Kosky, R., de Feria Silva, M., Posada Pérez, L., Gilliard, T., Bernal Martínez, F., Reyes Vega, M.et al. (2002). Somatic embryogenesis of the banana hybrid cultivar FHIA-18 (AAAB) in liquid medium and scaled-up in a bioreactor. Plant Cell Tissue Organ Cult. 68, 21-26. doi: 10.1023/A: 1012905825307

Gupta, P. K., and Timmis, R. (2005). Mass propagation of conifer trees in liquid cultures-progress towards commercialization. Plant Cell Tissue Organ Cult. 81, 339-346. doi: 10.1007/s11240-004-6654-1

Hamidah, M., Debergh, P., and Karim, A. G. A. (1997a). Cyclic somatic embryogenesis of Anthurium scherzerianum Schott. Acta Hortic. 447, 123-124. doi: 10.17660/ActaHortic.1997.447.15

Hamidah, M., Karim, A. G. A., and Debergh, P. (1997b). Somatic embryogenesis and plant regeneration in Anthurium scherzerianum. Plant Cell Tissue Organ Cult. 48, 189-193. doi: 10.1023/A:1005834131478

Kitamiya, E., Suzuki, S., Sano, T., and Nagata, T. (2000). Isolation of two genes that were induced upon the initiation of somatic embryogenesis on carrot hypocotyls by high concentrations of 2,4-D. Plant Cell Rep. 19, 551-557. doi: $10.1007 / \mathrm{s} 002990050772$

Klimaszewska, K., Hargreaves, C., Lelu-Walter, M. A., and Trontin, J. F. (2015). "Advances in conifer somatic embryogenesis since year 2000," in In Vitro Embryogenesis in Higher Plants, eds M. A. Germanà and M. Lambardi (New York, NY: Springer Science Business Media), 131-166.

Kuehnle, A. R., Chen, F. C., and Sugii, N. (1992). Somatic embryogenesis and plant regeneration in Anthurium andraeanum hybrids. Plant Cell Rep. 11, 438-442. doi: $10.1007 / \mathrm{BF} 00232686$

Kumria, R., Sunnichan, V. G., Das, D. K., Gupta S. K., Reddy V. S., Bhatnagar R. K., et al. (2003). High-frequency somatic embryo production and maturation into normal plants in cotton (Gossypium hirsutum) through metabolic stress. Plant Cell Rep. 21, 635-639. doi: 10.1007/s00299-002-0554-9

Kunisaki, J. T. (1980). In vitro propagation of Anthurium andraeanum Lind. Hort. Sci. 15, 508-509.

Lai, F. M., and McKersie, B. D. (1994). Scale-up of somatic embryogenesis in alfalfa (Medicago sativa L.) I subculture and indirect secondary somatic embryogenesis. Plant Cell Tissue Organ Cult. 37, 151-158. doi: 10.1007/ BF00043609

Lü, J., Chen, R., Zhang, M., Teixeira da Silva, J. A., and Ma, G. (2013). Plant regeneration via somatic embryogenesis and shoot organogenesis from immature cotyledons of Camellia nitidissima Chi. J. Plant Physiol. 170, 1202-1211. doi: 10.1016/j.jplph.2013.03.019

Martin, K. P., Joseph, D., Madassery, J., and Philip, V. J., (2003). Direct shoot regeneration from lamina explants of two commercial cut flower cultivars of Anthurium andraeanum Hort. In Vitro Cell. Dev. Biol. Plant 39, 500-504. doi: 10.1079/IVP2003460

Matsumoto, T. K., Webb, D. T., and Kuehnle, A. R. (1996). Histology and origin of somatic embryos derived from Anthurium andraeanum Linden ex André Lamina. J. Am. Soc. Hort. Sci. 121, 404-407.

Merkle, S. A., Parrott, W. A., and Williams, E. G. (1990). "Applications of somatic embryogenesis and embryo cloning," in Developments in Crop Science 19. Plant Tissue Culture: Applications and Limitations ed. S. S. Bhojwani (Amsterdam: Elsevier), 67-101. doi: 10.1016/B978-0-444-88883-9.50008-X

Mousavizadeh, S. J., Mashayekhia, K., and Hassandokht, M. R. (2017). Indirect somatic embryogenesis on rare octoploid Asparagus breslerianus plants. Sci. Hortic. 226, 184-190. doi: 10.1016/j.scienta.2017.08.031

Murashige, T., and Skoog, F. (1962). A revised medium for rapid growth and bioassay with tobacco tissue cultures. Physiol. Plant 15, 473-497. doi: 10.1111/j. 1399-3054.1962.tb08052.x

Pareek, A., and Kothari, S. L. (2003). Direct somatic embryogenesis and plant regeneration from leaf cultures of ornamental species of Dianthus. Sci. Hortic. 98, 449-459. doi: 10.1016/S0304-4238(03)00078-5
Pierik, R. L. M., Steegmans, H. H. M., and Van Der Meys, J. A. J. (1974). Plantlet formation in callus tissues of Anthurium andraeanum Lind. Sci. Hortic. 2, 193-198. doi: 10.1016/0304-4238(74)90009-0

Pierik, R. L. M. (1976). Anthurium andraeanum plantlets produced from in vitro cultivated callus cultures. Physiol. Plant. 37, 80-82. doi: 10.1111/j.1399-3054. 1976.tb01876.x

Pierik, R. L. M., van Leeuwen, P., and Rigter, G. C. C. M. (1979). Regeneration of leaf explants of Anthurium andraeanum Lind. in vitro. Neth. J. Agric. Sci. 27, 221-226.

Pinheiro, M. V. M., Martins, F. B., da Cruz, A. C. F., de Carvalho, A. C. P. P., Ventrella, M. C., and Otoni, W. C. (2013). Maturation of Anthurium andraeanum cv. Eidibel somatic embryos from nodal segments. In Vitro Cell Dev. Biol. Plant 49, 304-312. doi: 10.1007/s11627-0139522-z

Pinheiro, M. V. M., Martins, F. B., da Cruz, A. C. F., de Carvalho, A. C. P. P., de Oliveira, E. J., and Otoni, W. C. (2014). Somatic embryogenesis in anthurium (Anthurium andraeanum cv. Eidibel) as affected by different explants. Acta Sci. Agron. 36, 87-98. doi: 10.4025/actasciagron.v36i1.16557

Puchooa, D. (2005). In vitro mutation breeding of Anthurium by gamma radiation. Int. J. Agric. Biol. 7, 11-20.

Rueb, S., Leneman, M., Schilperoort, R. A., and Hensgens, L. A. M. (1994). Efficient plant regeneration through somatic embryogenesis from callus induced on mature rice embryos (Oryza sativa L.). Plant Cell Tissue Organ Cult. 36, 259-264. doi: 10.1007/BF00037729

Ruffoni, B., and Savona, M. (2005). The temporary immersion system (T.I.S.) for the improvement of micropropagation of ornamental plants. Acta Hortic. 683, 445-453. doi: 10.17660/ActaHortic.2005.683.59

Stasolla, C., and Yeung, E. C. (2003). Recent advances in conifer somatic embryogenesis: improving somatic embryo quality. Plant Cell Tissue Organ Cult. 74, 15-35. doi: 10.1023/A:1023345803336

Teixeira da Silva, J. A., Dobranszki, J., Winarto, B., and Zeng, S. J. (2015). Anthurium in vitro: a review. Sci. Hortic. 186, 266-298. doi: 10.1016/j.scienta. 2014.11.024

Tsay, H. S., and Huang, H. L. (1998). Somatic embryo formation and germination from immature embryo-derived suspension-cultured cells of Angelica sinensis (Oliv.) Diels. Plant Cell Rep. 17, 670-674. doi: 10.1007/s0029900 50463

von Arnold, S., Sabala, I., Bozhkov, P., Dyachok, J., and Filonova, L. (2002). Developmental pathways of somatic embryogenesis. Plant Cell Tissue Organ Cult. 69, 233-249. doi: 10.1023/A:1015673200621

Witjaksono, L., and Litz, R. E. (1999). Maturation of avocado somatic embryos and plant recovery. Plant Cell Tissue Organ Cult. 58, 141-148. doi: 10.1023/A: 1006344127546

Xin, W. J., Xu, B., Wang, G. D., Guo, W. M., Wen, F. D., and Jin, J. P. (2006). Somatic embryogenesis and plant regeneration of Anthurium andraeanum. Acta Hortic. Sinica 33, 1281-1286. doi: 10.3321/j.issn:0513-353X.2006. 06.020

Zhou, X., Zheng, R., Liu, G., Xu, Y., Zhou, Y., Laux, T., et al. (2017). Desiccation treatment and endogenous IAA levels are key factors influencing high frequency somatic embryogenesis in Cunninghamia lanceolata (Lamb.) Hook. Front. Plant Sci. 8:2054. doi: 10.3389/fpls.2017.02054

Conflict of Interest Statement: The authors declare that the research was conducted in the absence of any commercial or financial relationships that could be construed as a potential conflict of interest.

Copyright $\odot 2019$ Wang, Xu, Yan and Xu. This is an open-access article distributed under the terms of the Creative Commons Attribution License (CC BY). The use, distribution or reproduction in other forums is permitted, provided the original author(s) and the copyright owner(s) are credited and that the original publication in this journal is cited, in accordance with accepted academic practice. No use, distribution or reproduction is permitted which does not comply with these terms. 